\title{
Implementation of Automatic Solar Tracking to Maximize Illumination and High Battery Storage
}

\author{
Charapale Arti ${ }^{1}$, Gujar Mousami ${ }^{2}$ \\ Student, Electronics and Telecommunication Department, DACOE, Karad, India ${ }^{1}$ \\ Assistant Professor, Electronics and Telecommunication Department, DACOE, Karad, India ${ }^{2}$
}

\begin{abstract}
The solar tracking system is controlled by PIC microcontroller depending upon the control signal given in this technological world. The need for renewable energy resources has been very essential rather than non-renewable resources, because cost of the non-renewable resources sums to be a larger one and it will not provide an ecofriendly environment. So, in this concept we introduce the Parabolic Solar Tracking System instead of the flat solar tracking system which is very common in our day today life. By implementing parabolic solar tracking system, which uses the multifunction solar cells with parabolic mirror reflectors the efficiency can be improved up to $39.2 \%$ compared to the single junction cells. This enhanced feature is due to the infinite number of junction in the multifunction solar cell and the shape of the reflectors that is designed. The tracking system is controlled by PIC microcontroller depending upon the control signal given by LDR.
\end{abstract}

\section{INTRODUCTION}

This Paper display a model of hybrid power generation by non-conventional energy, renewable and environment using solar power and gives a power generating method friendly energy resources is vital for steering the global from sunrays or light. That method of power generation is energy supplies towards a sustainable path. Nuclear deal is simple and is taken from natural resource. This needs only going to help our power sector. We have need lots of extra maximum sunlight to generate power. This paper power to keep the momentum of growth going to realize helpful to for power generation by setting the equipment to the dream of our more than one billion people. It will not get maximum sunlight automatically. This system is readily solve our energy problems.

tracking for maximum intensity of light. If when there is decrease in intensity of light, this system automatically changes to its direction to get maximum intensity of sunrays or light. We are using three sensors in three directions to sense the direction of maximum intensity of light. The difference between the outputs of the sensors is given to the microcontroller unit. We are using the microcontroller for tracking and generating power from sun-light. It will process the input voltage from the comparison circuit and control the direction in which motor will be rotated so that it will be receive maximum intensity of light from the sun.

\section{HISTORICAL BACKGROUND}

Energy is the key input to drive and increase the life cycle. Primarily; it is the well gift of the nature to our in various forms. The consumption of energy is directly proportional to the progress of the mankind. With ever increasing population, improvement in the living standard of the humanity, industrialization of the developing many countries, the globalmainly demand for energy is expected to increase the rather significantly in the near future. The mainly primary source of energy is fossil fuel, however finiteness of fossil fuel large scale as well as reserves environmental degradation caused by their widespread use. The Particularly global warming, urban air Pollution and acid rain, There are strongly suggest that harnessing of

We need to tap other sources of power as well, like the renewable sources such as wind power, hydroelectricpower, tidal power etc. It needs a lot of vision. Though, participation of youth is happening but it requires more intensity. Twenty years ago, the Atomic Energy Commission was laid down a target of 10,000 MW of electricity generation by the end of 20th century.

Today, in 2010 our capacity is about 4,200 MW and due to shortage of uranium many of these plants are operating at much below their capacity. Therefore, there is need of the non-conventional energy in large scale still now. Energy is stored in a lead acid battery and is made to charge an emergency light and is made to glow during night time.

\section{A) Solar Energy:}

The Energy is released by sun as the electromagnetic wave. That energy reaching the earth's atmosphere consists of about $8 \%$ UV radiations, $46 \%$ are visible light and $46 \%$ infrared radiations. There are Solar energy can be used in two ways as solar heating and solar electricity.

There are Solar heating is to capture sun's energy for heating buildings and for food stuffs etc. Solar electricity is mainly produced by using photovoltaic solar cells which are made of semiconductor materials that directly convert sunlight into electric power. 


\section{LITERATURE SURVEY}

1]The Microcontroller based solar tracking system and its implementation: Okan Bingul,Ahmet Altintas, Yusuf Oner was tested the solar tracking system experimentally and their experimental study has realized that when two solar collector panels, one was stationary and another was rotary in which stationary panel was tilted at fixed elevation angle and was oriented in some azimuth angle.The LDRs assembly was mounted on the rotary one and the temperature of panels verses time was measured with minute interval and the results found are that the rotary panel containing solar tracking system takes more light intensity than stationary panel.

2]Automatic solar tracking system to maximize power extraction:Dr.PremKumar,P.HarwashKumar,M.InduPriya nga,B.Saranya,M.Rahul they have dwascussed that tracking system which uses the parabolic dwash and concentrated solar cell we can improve efficiency of the few percent compared to the normal methods which uses single junction cell. It was used to provide a clean environment for the future generation.

\section{WORKING PRINCIPLE}

A) Working principle of the tracker:-

In this system tracking device in out prototype. It was the one which follows the sun's movement throughout the day and provides uninterrupted reflection to the solar panel. The sun rays will fall on the solar panel in two ways, which was, they will fall directly on the solar panel and also the reflector will reflect the incident rays on the solar panel. Suppose at the time of sun raise the sun was in extreme east the reflector will align itself in some position by which the incident rays will fall on the solar panel. Now when earth rotates and the sun gets shifted from its earlier position the reflection of the incident rays will also change. Thus as a result the light will fall on the sensors kept on each side of the solar panel equipment. The tracking the circuit was so designed that when reflection falls on the sensor attached to the right of the panel, tracker will move wards the left, and vase-versa. Similarly was the case when the reflection falls on the sensor attached at the top of the panel system, circuit will make the tracker to move to the downwards side. We have tried to bring two simple principles are together. One being, the normal principle of incidence and reflection was on which our tracker works. And the other was the principle on which the solar panel are be works, which was on the incidence of the solar rays the photovoltaic cells, will be produce electricity.

b) Need of A Solar Tracker:-

There Photovoltaic's was the area of technology and research are related to the application of the solar cells as solar energy. Solar cells have lot of applications. Individual cells are most used for powering small devices such as electronic calculators. Photovoltaic arrays generate a form of renewable electricity, particularly useful in the situations where electrical power from the grid was unavailable such as the in water pumping applications, Earth-orbiting satellites and space probes, remote radiotelephones and remote area power systems. The Photovoltaic electricity was also increasingly deployed in grid-tied electrical systems. Renewable energy was rapidly gaining importation as an energy resource as fossil fuel prices fluctuate. One of the most popular renewable energy sources was solar energy or sunlight energy. Many researches was conducted to develop some methods to increase the efficiency of Photo Voltaic systems (or solar panels). One such method is to employ a solar panel tracking system.

\section{METHODOLOGY}

A)Block diagram:

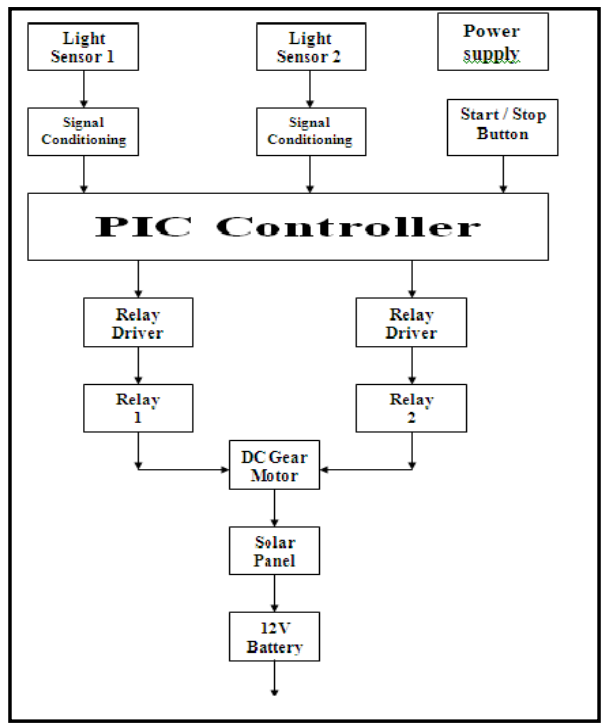

Fig. No.1 Block Diagram

B) Block Diagram Description

The Implementation of Automated Solar Tracking system has following components:

1. The Light sensor

2. Signal Conditioning circuit

3. PIC Microcontroller

4. Relay Driver \& Motor

5. Solar panel

6. Start / stop switch

7. Power supply

8. Battery

9. Inverter

a) Light Sensor:

There was one of the main part of our Paper. The main intention of there was block was to sense the light. For sensing light we are using the light dependent ringmaster (LDR). By using thwas sensor and its related circuit diagram we can control the direction of solar panel. 
IARJSET

b). Signal Conditioning:

Output of light sensor was given to signal conditioning block. Signal conditioning means converting input according to requirement of next stage. The next stage was microcontroller. Its requirement was either logic 0 signals or logic 1 signals So there was block will convert low resistance i.e. light condition into logic 1 and high resistance i.e. dark condition into logic 0. For there was purpose we are using Comparator LM339.

c) PIC Microcontroller:

- There was Only 35 single-word instructions to learn.

- All single-cycle instructions are except for program branches, which are two-cycle.

- Operating speed: DC - $20 \mathrm{MHz}$ clock input.

- Up to $8 \mathrm{~K}$ x 14 words of Flash Program Memory and Up to $368 \times 8$ bytes of Data Memory (RAM), as well as Up to $256 \times 8$ bytes of EEPROM Data Memory.

- Pin out compatible to other 28-pin or 40/44-pin PIC16CXXX and PIC16FXXX microcontrollers.

d) Peripheral Features:

- Timer0: 8-bit timer/counter with 8-bit pre scalar.

- Timer1: 16-bit timer/counter with pre scalar, can be incremented during Sleep via external crystal/clock and Timer2: 8-bit timer/counter with 8-bit period resistor , presale and post scalar.

- Two Capture, Compare, PWM modules

- Resolution was 12.5 ns. Capture was 16-bit, max.

- Compare was 16-bit, max. Resolution was 200 ns.

- PWM max. Resolution was 10-bit

e) Relay Driver and Motor

There was block has the potential to drive the various controlled the devices. In there was block mainly we are useful the translators and relays. There are total 2 relay driver circuits we are using to control the direction of DC gear motor. Output signal from PIC controller are given to the base of translator, which we are further energizing particular relay.

Because of there was appropriate device was selected and it do its allotted function. Relay first and second are used to control the direction of the DC motor. If relay first was turned $\mathrm{ON}$ then DC motor will rotate in Clockwise direction and if relay second was turned $\mathrm{ON}$ then DC motor will rotate in Anti-Clockwise direction.

\section{E) The Solar Panel}

The Solar cells convert sunlight directly into electric power or electricity. Solar cells are often used to power calculators and watches. They are made of semiconducting materials similar to those used in the computer chips. When sunlight was absorbed by these materials, the solar energy knocks electrons loose from their atoms, allowing the electrons to flow through the material to produce electricity. There was process of converting light (photons) to electricity (voltage) was called the photovoltaic (PV) effect. f) Start / Stop Switch:

These switches are used to start the system and stop the system. These are push to ON switches. Normally it gives logic 1 . And when it was pressed it gives logic 0 .

\section{g) Power supply:}

Here we used the $+5 \mathrm{v}$ and $+12 \mathrm{v}$ dc power supply. The main function of was block was to provide the required amount of voltage to essential circuits. $+5 \mathrm{~V}$ dc was given to Light sensor, signal conditioning, microcontroller, start / stop button etc. and $+12 \mathrm{~V}$ was given to relay driver, relay and DC gear motor.

\section{h) Battery:}

We are using $12 \mathrm{~V}, 1.2 \mathrm{AH}$ battery to store the energy from solar. There was energy i.e. DC supply has used to give the supply to our entire project as well as inverter to get 230V ac Supply.

\section{I) Inverter:}

In our system we are using inverter. Inverter will take input from DC Battery and convert that $12 \mathrm{~V}$ dc voltage into $230 \mathrm{~V}$ ac output voltage. There was $230 \mathrm{~V}$ ac output can be useful for various applications like switch on the lights, water pump, fan.

\section{HARDWARE DETAILS}

a) Solar Panel:

Solar cells are convert sunlight directly into electricity or electrical power. Solar cells are often useful to power calculators and watches. They are made of semiconducting materials similar to those used in the computer chips. When sunlight was absorbed by these materials, the solar energy knocks electrons loose from their atoms, allowing the electrons to flow through the material to produce electricity. There was process of converting light (photons) to electricity (voltage) was know as the photovoltaic (PV) effect.

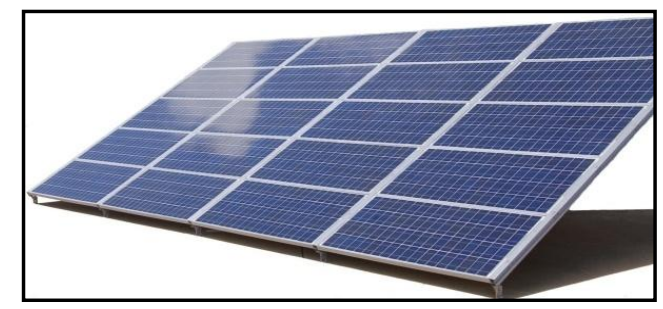

Fig.2 Solar Panel

b) Battery:

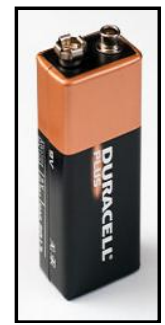

Fig.3 Battery 
We are using $12 \mathrm{~V}, 1.2 \mathrm{AH}$ battery to store the electric energy from solar. There was energy i.e. DC supply was used to give the supply to our entire system as well as inverter to get 230 Vac supply.

\section{C) Inverter:}

In our project we are using inverter. Inverter will take input from DC Battery and convert that $12 \mathrm{~V}$ dc voltage into $230 \mathrm{~V}$ ac output voltage. There was $230 \mathrm{~V}$ ac output can be used for various applications like switch on the lights, fan, water pump etc.

\section{d)LDR:}

There was one of the main part of our system. The main intention of was block was to sense of the light. For sensing light we are using the light dependent regwaster (LDR). By using the was sensor and its related circuit diagram we can control the direction of solar panel.

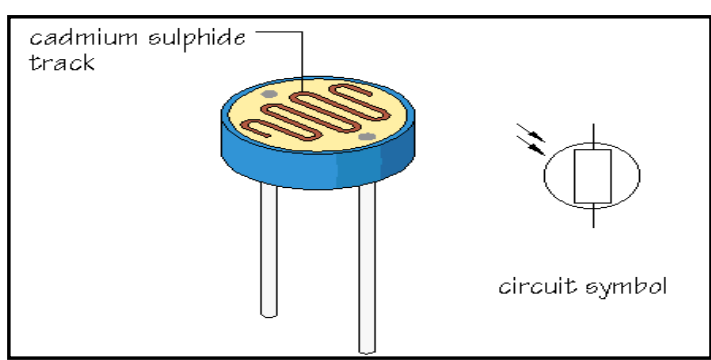

Fig4.4LDR

\section{SOFTWARE DETAILS}

A) PIC Microcontroller:

- There are Only 35 single-word instructions to learn and all single-cycle instructions except for program branches, which are two-cycle.

- Operating speed: DC $-20 \mathrm{MHz}$ clock input.

- Up to $8 \mathrm{~K}$ x 14 words of Flash Program Memory,

Up to $368 \times 8$ bytes of Data Memory (RAM),

Up to $256 \times 8$ bytes of EEPROM Data Memory.

- Pin out compatible to other 28-pin or 40/44-pin

PIC16CXXX and PIC16FXXX microcontrollers.

B) Peripheral Features:

- Timer0: 8-bit timer/counter with 8-bit prescaler.

- Timer1: 16-bit timer/counter with prescaler, can be incremented during Sleep via external crystal/clock.

- Timer2: 8-bit timer/counter with 8-bit period regwaster, prescaler and postscaler.

- Two Capture, Compare, PWM modules:

- Capture was 16-bit, max. resolution was $12.5 \mathrm{~ns}$.

- Compare was 16-bit, max. resolution was 200 ns.

- PWM max. resolution was 10-bit.

- Universal Synchronous Asynchronous Receiver Transmitter (USART/SCI) with 9-bit address detection.

- Parallel Slave Port (PSP) - 8 bits wide with external RD,

WR and CS controls (40/44-pin only).

- Brown-out detection circuitry for Brown-out Reset (BOR).

\section{ADVANTAGES AND APPLICATION}

a) Advantages:

1. More energy absorption.

2. More energy generation.

3. Low maintenance cost.

b) Applications:

1. Home.

2. Hospitals.

3. Colleges.

4. Agriculture.

\section{FUTURE SCOPE}

The heat that was generated during the process sums to a large amount which was wasted by the process of vaporization. So, we plan to convert the waste resource into useful one by using the thermal generator. The thermal generator was a one which converts the heat energy directly into an electrical form. By implementing was technique we can further improve the efficiency.

\section{ACKNOWLEDGEMENT}

We express our sincere thanks to Ms. Gujar M.P. whose supervision, inspiration and valuable discussion has helped us tremendously to complete our project. His guidance proved to be the most valuable to overcome all the hurdles in the fulfillment of this Project. We grateful to Prof. Chorge P. J. for direct or indirect help in the completion of this project. Last but not least, this acknowledgement would be incomplete without rendering my sincere gratitude to all those who have helped us in the completion of this project.

\section{CONCLUSION}

The parabolic and concentrated solar cell we can improve the efficiency to a few percent compared to the normal method which uses the single junction cell. Further, we can save the material consumption when the concentrated cells are used and provide a clean environment Thus, by the implementation of the tracking system which uses for the future generation.

\section{REFERENCES}

1) David Appleyard, "Solar Trackers: Facing the Sun", Renewable Energy World Magazine, UK: Ralph Boon, June 1, 2009. Okan Bingul,Ahmet Altintas, Yusuf Oner, "Microcontroller based solar tracking system and its implementation" Renewable Energy World Magazine, UK: Ralph Boon, June 1, 2009.

2) Dr.PremKumar,P.HarwashKumar,M.InduPriyanga,B.Saranya,

M.Rahul, "Automatic solar tracking system to maximize power extraction" Renewable Energy World Magazine, UK: Ralph Boon, June 1, 2009.

3) www.wikipidia.com.

4) www.electronicsforu.com. 